\title{
RELIGION WITHOUT GOD: EL DESAFÍO DEL POSTSECULAR
}

\author{
Anna Cavaliere \\ Università degli Studi di Salerno
}

\section{Una definición de postsecular}

El mundo occidental parece sufrir -tal como escribe Gian Enrico Rusconi- del síndrome del post: "nada revela mejor la incapacidad de definir las características de nuestro tiempo $[\ldots]$ como el uso ya coactivo de la partícula post». ${ }^{1}$ La época contemporánea se define, pues, posmoderna, ${ }^{2}$ posdemocrática, ${ }^{3}$ postsecular. ${ }^{4}$ Este último adjetivo se utiliza a menudo con el propósito de describir la significativa reaparición de la religión en la esfera pública de los Estados liberales, a la que hemos asistido en los últimos años. De manera particular, en el ámbito de una crisis radical que caracteriza a las democracias contemporáneas, a menudo se ha recurrido a un uso abiertamente 'político' de la religión: por una parte, intentando devolver a las confesiones religiosas -respecto de asuntos los más variados- el monopolio de una moral 'verdadera' y 'natural', encomendándoles el papel de poseedoras y de intérpretes de una 'Verdad' última, vinculante para todos; por otra parte, atribuyendo a los credos religiosos un impactante valor simbólico e identitario, convirtiéndolos en caracterizadores de una identidad cultural que, en un relato ejemplificado de las relaciones sobrenacionales e interculturales, se presenta con unos caracteres claros (por ejemplo, los de Occidente o de Europa frente a la 'emergen-

\footnotetext{
1. G. E. Rusconi, Cosa resta dell'Occidente, Laterza, Roma-Bari, 2012, p. 3.

2. Para una primera presentación del concepto de posmodernidad, cfr. G. Chiurazzi, Postmoderno, Bruno Mondadori, Milano, 2002. Bazzicalupo subraya el carácter parcialmente desorientante de la expresión: "La fase actual de la modernidad, que no se debería lllamar posmoderna a pesar de que vuelque algunos rasgos de la modernidad, no parece representar una salida de la modernidad sino una radicalización de sus rasgos" (L. Bazzicalupo, Politica, identità, potere. Il lessico politico alla prova della globalizzazione, Giappichelli, Torino, 2004, p. 7).

3. C. Crouch, Postdemocrazia, tr. it. de C. Paternò, Laterza, Roma-Bari, 2009.

4. Para un análisis global de los problemas concernientes la edad postsecular, cfr. E. Rusconi (ed.), Lo Stato secolarizzato nell'età post-secolare, Il Mulino, Bologna, 2008.
} 
cia Islam'). ${ }^{5}$ De esa manera, las agencias religiosas han vuelto a 'darse a conocer' en el escenario público en un proceso que ha sido definido una verdadera 'publicización' de las creencias privadas. ${ }^{6}$ Todo esto ha llevado a la sensación de una profunda inadecuación de la dicotomía poder político-poder religioso a la hora de describir la dialéctica existente en los ordenamientos llamados postseculares: una sensación que, inevitablemente, interpela a los teóricos de la democracia.

\section{Religion without God}

En este contexto se inserta la reflexión de Ronald Dworkin, contenida en el libro Religion without God. ${ }^{7}$ La obra se sustenta alrededor de una peculiar acepción de la religión: "Religion is a deep, distinct, and comprehensive worldview: It holds that inherent, objective value permeates everything, that the universe and its creatures are awe-inspiring, that human life has purpose and the universe order" ${ }^{8}$ Por lo tanto, la religión representa una aproximación a la vida basada en dos premisas: el reconocimiento del valor de la vida humana, y la convicción de que represente una manifestación de lo sublime. El hecho de que "it matters objectively how a human life goes" " constituye uno de los cimientos del pensamiento de Dworkin. De eso procede un importante corolario: la innata capacidad humana -que, al mismo tiempo, es una responsabilidad- de actuar para que su propia vida sea una vida buena. En Justicia para erizos, Dworkin sostiene que "We must recognize, as cardinal among our private interests, an ambition to make our lives good lives: authentic and worthy rather than mean or degrading. In particular we must cherish our dignity". ${ }^{10}$ Para Dworkin, la actitud religiosa toma en serio esta responsabilidad. Y, además, eso se manifiesta en la mirada de cada hombre respecto del universo. El individuo religioso detecta en la naturaleza un valor intrínseco: la observa embobado, su mirada es como "The enchantment is the discovery of transcendental value in what seems otherwise transient and dead". ${ }^{11}$

Relacionando el concepto de religión con tales presuposiciones, es posible superar la tradicional distinción -que él considera angosta y desorientante- entre religiosos y no

5. G. Preterossi (ed.), Le ragioni dei laici, Laterza, Roma-Bari, 2005.

6. M. Gauchet, Le Désenchantement du monde. Une histoire politique de la religion, Galimard, Paris, 1985.

7. R. Dworkin, Religion Without God, Harvard University Press, Cambridge, (Mass.), 2013.

8. Ibid., p. 1.

9. Ibid., p. 24

10. R. Dworkin, Justice for Hedgehogs, Harvard University Press, Cambridge (Mass.), 2013, p. 13.

11. R. Dworkin, Religion without God, p. 12. 
religiosos, y considerar como hombres de fe a todos los que sienten -como evidencia Albert Einstein-que "what is impenetrable to us really exists, manifesting itself as the highest wisdom and the most radiant beauty which our dull faculties can comprehend only in their most primitive forms". ${ }^{12}$ Tal acepción de la religión le permite a Dworkin establecer un paralelo entre la ciencia y la fe, y poner de manifiesto las recíprocas semejanzas. Ambas poseen la que él define 'a strong integrity'. ${ }^{13}$ La ciencia manifiesta esta integridad por medio de su propia exhaustividad lógica: piénsese en los principios físicos generales que no pueden ser ni siquiera parcialmente desmentidos sin que la totalidad del modelo teórico de referencia no se ponga en tela de juicio; y la fe, mediante un significativo componente de valores, que revela una coherencia interna difícil de confutar. Además, la fe y la ciencia están caracterizadas por un notable nivel de presuposición: implican, pues, la 'entrega' del sujeto. Lo cual parece descontado en el caso de la religión, 'fe por excelencia', pero - para Dworkin- ella se verifica también en el caso del saber científico. El ejemplo nos lo proporciona una vez más la física: de momento, las teorías producidas solo explican una mínima parte de lo existente: "Physicists sense and claim beauty, that is, in a totality of existence of which they are mainly ignorant": ${ }^{14}$ por lo tanto, su 'fe' es el motor de su curiositas. ${ }^{15}$

\section{La libertad religiosa como independencia ética}

Dentro de las obras más relevantes, la interpretación de la religión de Dworkin se basa en The will to believe de William James. ${ }^{16}$ Este mismo autor había inspirado, a finales de los años noventa, las Gifforde Lectures de Charles Taylor, llamadas Living in a secular age ${ }^{17}$ aportando una significativa contribución a un itinerario de investigación que culmina en La edad secular. ${ }^{18}$ La interpretación propuesta por Taylor acerca de los textos de James presenta, al mismo tiempo, muchas semejanzas con la reflexión de Dworkin, así como notables diferencias. No alejándose mucho de lo afirmado por Dworkin, para Taylor, en la edad contemporánea, la distinción entre creyentes y no

12. A. Einstein, en E. Fadiman (ed.), Living Philosophies: The Reflections of Some Eminent Men and Women of Our Time, Doubleday, New York, 1990, p. 6.

13. R. Dworkin, Religion without God, p. 86.

14. Ibid., p. 60.

15. Por lo que a la centralidad de la curiositas en el paradigma moderno se refiere, cfr. H. Blumenberg, Die Legitimität der Neuzeit, Surhkamp, Frankfurt am Main, 1966.

16. W. James, The Will to Believe (1896), Cosimo, New York, 2007.

17. P. Costa, Introduzione en C. Taylor, Incanto e disincanto, P. Costa (ed.), Edizioni Dehoniane, Bologna, 2014.

18. C. Taylor, A Secular Age, The Belknap Press of Harvard University Press, Cambridge (Mass.), 2007. 
creyentes poco a poco pierde relevancia. Taylor pone de manifiesto que el actual es un proceso de 'optionalization of faith': mejor dicho, se pasa de un mundo en el que la fe parece ser la única opción posible, a uno en el que ella puede ser parangonada -por lo que a la legitimidad ética se refiere- a la no fe. Sin embargo, en la teoría de Taylor no se halla un elemento que, en la elaboración de Dworkin, aparece como dirimente: la descripción de un 'doble nivel' de las religiones, sobre la base del que ellas presentan un aspecto científico, que concierne el nacimiento del universo y al origen de la vida, y uno valorial, que expresa el nivel del 'deber ser' respecto de la existencia. Los dos aspectos no se pueden sobreponer: sobre la base de la ley de Hume, es posible afirmar que de la parte científica de las religiones no puede derivar la valorial y, por lo que a esta última se refiere, es posible que creyentes y no creyentes puedan coincidir en algunos temas. Para Dworkin, los hombres disponen, por lo general, de la capacidad de crear, por medio de la argumentación racional, un espacio de verdad moral, dentro del cual pueden estructurarse los juicios de valor. ${ }^{19}$ Siempre en Justice for Hedgehogs, , él sostiene que "Value judgments are true, when they are true, not in virtue of any matching but in view of the substantive case that can be made for them. Te moral realm is the realm of argument". ${ }^{20}$ La enseñanza que procede de Religion without God es que a esta regla, que establece una relación apremiante entre el horizonte de los valores y la argumentación racional, también pueden someterse los valores religiosos. Es cuando estos se insertan en el círculo de la argumentación que revelan el potencial inclusivo y acogedor del 'deber ser religioso'.

Para Dworkin, Religion without God representa la ocasión de apartarse tanto del liberalismo de matriz rawlsiana ${ }^{21}$ como de las últimas tesis de Jurgen Habermas. A través de la teoría del overlapping consensus, Rawls ha teorizado la posibilidad para los ciudadanos -a partir de su visión comprensiva, es decir, de las propias motivaciones religiosas, filosóficas y morales- de llegar a compartir la visión política liberal dentro de un 'espacio neutral' para la argumentación racional. ${ }^{22}$ La visión de Dworkin pretende poner de manifiesto que también este tipo de 'filtro liberal' puede actuar de manera discriminatoria. Su propuesta para reglamentar el acceso de las confesiones religiosas a un espacio público laico ${ }^{23}$ se realiza con la transformación del principio de libertad

\footnotetext{
19. Cfr. V. Giordano, Il positivismo e la sfida dei principi, Esi, Napoli, 2004, pp. 166 ss.; Id., Principi, ragioni, convenzioni sociali. Letture asimmetriche del costituzionalismo conmtemporaneo, in A. Tucci, V. Giordano, Razionalità del diritto e poteri emergenti, Giappichelli, Torino, 2013, pp. 49-64.

20. R. Dworkin, Justice for Hedgehogs, p. 11.

21.S. Guest, Ronald Dworkin: Third Edition, Stanford University Press, Stanford, 2013.

22. J. Rawls, A Theory of Justice, Oxford University Press, London, 1973.

23. Sobre la relación entre religión y laicidad de la esfera pública, cfr. R. Dworkin, Is Democracy Possible Here? Principles for a New Political Debate, Priceton University Press, Princeton, 2006, en particular Cap. III.
} 
de religión en la forma más extensa del derecho a la independencia ética. Este derecho se les puede reconocer de manera indiferente a todos los individuos, para solucionar $a b$ origine el problema de la paridad de las condiciones a la hora de acceder al debate público. Sin embargo, este tipo de solución no considera a la peculiaridad de las argumentaciones que presentan una matriz religiosa, que ha sido ampliamente puesta en evidencia por Jurgen Habermas. ${ }^{24}$ Este autor, que en los últimos años se ha interesado mucho por la contribución cognitiva que los argumentos religiosos pueden aportar al debate público, ha hecho hincapié sobre la necesidad de que ellos deben someterse a una 'traducción' que pueda permitirles ser comprendidos tanto para los creyentes como para los no creyentes.

En conclusión, la tesis de Dworkin se aleja de aquellas teorías de la secularización centrales en el debate filosófico europeo, que parten del tema del conflicto y guardan el imprinting histórico-filosófico del nacimiento del Estado moderno, justo después de las guerras de religión. ${ }^{25}$ En su tentativa de acercar religión y ciencia, intencionalmente Dworkin desatiende el aspecto dogmático de las religiones y, aun mencionando el espectro de los conflictos religiosos, considera el carácter polemógeno de la religión un problema superable y, en parte, ya superado, ${ }^{26}$ mejor dicho, ya no es sino la sombra de lo que era, puesto que se manifiesta en la forma 'soft' de la disputa entre creyentes y no creyentes.

\author{
Traducción del italiano de M. Colucciello
}

24. J. Habermas, Nachmetaphysisches Denken II Aufsätze und Repliken, Suhrkamp Verlag, Berlin, 2012; J. Habermas, J. Ratzinger, Was die Welt Zusammenhält. Vorpolitische Moralische Grundlagen eines Freihaitlichen Staates, Katholische Akademie, Bayern, 2004.

25. E. W. Böckenförde, Diritto e secolarizzazione, tr. it. de G. Preterossi, Laterza, Roma-Bari, 2006; A. Catania, Lo Stato moderno, Giappichelli, Torino, 1996.

26. R. Dworkin, Religion without God, p. 137. 